\title{
Network Misconduct of College Students and Regulatory Emotional Self-Efficacy
}

\author{
Huiying Liu, Bian Du* \\ Educational Department of Zhengzhou University, Zhengzhou, Henan, China \\ Email: liuhy@zzu.edu.cn, ${ }^{*}$ dubiango@163.com
}

Received February 2014

\begin{abstract}
Purposes: Analyze characteristics of network misconduct of college students and study its correlation with regulatory emotional self-efficacy through scale survey of network misconduct of college students. Methods: Conduct the test on 1321 college students by using the scale of network misconduct and regulatory emotional self-efficacy of college students. SPSS was used to compile effective data. Statistical analysis was made using descriptive statistics, independent sample $t$ test and one-way analysis of variance. Results: 1) $M \pm$ SD for network words anomie, study anomie and infringement are: $8.76 \pm 2.07 ; 7.40 \pm 2.17 ; 5.21 \pm 2.16$. 2 ) There are significant differences of network misconduct of college students on genders, education levels, majors and grades. $(t=12.510$, $\mathrm{p}<0.001 ; \mathrm{t}=50.957, \mathrm{P}<0.001 ; \mathrm{t}=23.840, \mathrm{p}<0.001 ; \mathrm{t}=28.576, \mathrm{P}<0.001$ ). 3 ) Conclusions of significantly negative correlation between regulatory emotional self-efficacy and network misconduct $(r=-0.134, p<0.01)$. For college student, network misconduct includes network words anomie, study anomie and infringement behavior, among which, network words anomie is more prominent; and self-efficacy concerning college students' emotion regulation has significantly negative correlation with network misconduct.
\end{abstract}

\section{Keywords}

College Students, Network Misconduct, Emotional Self-Efficacy

\section{Introduction}

Network misconduct means that in the network society built on the basis of internet, behavior of people violates certain social norms and behavior codes that are to be followed and displays deviation in the fictitious space as well as the behavior deviation due to misuse of internet [1]. Due to the fast development of internet, the population of net citizen has been increasing year by year. According to relevant reports of China Internet Network Information Centre, till the end of June, 2013, the population of net citizen has reached 591 million; and more than $90 \%$ of college students are using internet. Network has influenced the college students more in their behavioral pattern, value orientation, political attitude, moral sense and other aspects; network misconduct of college students has become a common phenomenon [2]. Different kinds of network misconduct will generate different harms to the society, mainly including four aspects that: spreading bad information will be harmful to the socie-

*Corresponding author. 
ty; rights and interests of various behavioral agents will be harmed; self-disorder of individuals as agent of network behavior will be harmful to the body and the mind; and it may even interrupt or hinder the normal operation of the "network society" [3]. Some researchers point out that there are three kinds of network misconduct, i.e. behavior lacking moral regulations, such as rumors online, abusive comments and personal attacks, addiction to games or internet, etc.; behavior conflicting with moral regulations, such as cyber pornography, privacy of celebrities, etc.; and extreme misconduct, such as network virus, hacker, network fraud, etc. [4]. In the aspect of investigation of network misconduct, research result by Zhou Lanfeng, a domestic scholar, shows that network misconduct of college students who were born after 1990 mainly include uploading at will, making follow-up comments at will and aimlessly, spreading pornographic and violent information, misleading other net citizens and even affecting normal orders of the society [5]. Yu Honglei prepares the questionnaire of network misconduct of college students including six dimensions, i.e. internet addiction, network lie, internet abusive comments, network infringement, cyber pornography and hacker [6]. In addition, there are studies in network misconduct of college students; for example, Hu Zhihai conducts experimental study on the implicit aggressivity and implicit self-esteem of college students with network misconduct by adopting implicit association test (IAT) and conducts comparison with the explicit questionnaire survey results [7]. It is found that compared with the civilization team, people with network misconduct demonstrate a high-level aggressivity and low-level self-esteem in both explicit and implicit senses. Researches by Zhang Wenming [8], Zhang Jingsheng [9] focus on the majors of ideology and politics, education and law.

Based on the researches by the above-mentioned scholars, this study finds out that network misconduct should have the following characteristics: First, it is problematic. Network misconduct is abnormal problem behavior against network moral regulations and codes. Second, it is harmful. The result of the behavior may cause harm and threat to body, mind, rights and interests of oneself or other members of the network society and may even interrupt or hinder the normal operation of the network society; Third, it is non-pathological. Pathological internet use means the phenomenon that the overusing of internet due to losing control of accessing the internet causes evident psychological depression and time consumption as well as problems or obstacles in the social interaction and family relationships. Some scholars maintain that pathological network use is "internet addiction disorder" (IAD in short), which mainly means that behavior of overindulging browsing, playing games online or building interpersonal relationships through network which cause negative effects for the addict. Matchell defines it as "anxious and emotional behavior occurring after compulsive overuse of internet and deprivation of access of internet" [10]. Internet addiction disorder has been involved in the treatment; object of this study is the non-pathological network misconduct. Fourth, it is implemented on the network. It excludes the unethical behaviors conducted in the real society due to bad influence from the internet. For example, stealing money due to lack of money to play online games belongs to illegal activity in real society. According to the four characteristics of the network misconduct, this study redefines the concept of network misconduct and maintains that network misconduct means the behavior in the network society built on the basis of the internet violating requirements of network regulations and codes, the result of which may cause danger and harm to body, mind, rights and interests of oneself or other members of the network society and may even interrupt or hinder the normal operation of the network society and the development of the society in the long run. The scale for network misconduct of college students shall be prepared and survey shall be conducted according to the scope and content of this definition; at the same time, relation between network misconduct of college students and emotional self-efficacy shall be studied, and the factors influencing network misconduct of college students shall be further explored.

\section{Objects and Methods}

\subsection{Objects}

Random sampling of whole classes is adopted. 1321 college students from colleges or universities in Henan Province were chosen as objects for questionnaire survey; 1400 questionnaires are handed out, 1317 effective questionnaires are recovered and the effective recovery rate is $94.36 \%$. Among the research objects, there are 629 male students and 688 female students; 311 are only-child and 1006 are children with siblings; there are 256 freshmen, 654 sophomores, 303 junior students and 104 senior students; 528 of them are majored in arts, 194 are majored in science, 417 are majored in engineering and 178 are majored in medicine. 


\subsection{Measuring Tool}

\subsubsection{Self-Made Scale of Network Misconduct of College Students}

The scale contains 15 items and three dimensions, i.e. network words anomie, network study anomie and network infringement. Internal consistency reliability of the scale is 0.82 ; correlation coefficient among different dimensions is significantly correlated at 0.01 level and values are from 0.250 to 0.463 ; correlation coefficient of the scale and dimensions is from 0.607 to 0.799 which is higher than the correlation coefficient among different dimensions; the structure of the scale is rational.

\subsubsection{Regulatory Emotional Self-Efficacy, Chinese Version of RES (Caprara)}

RES includes three dimensions, i.e. perceived self-efficacy in expressing positive affect (POS), perceived selfefficacy in managing despondency/distress (DES) and perceived self-efficacy in managing anger/irritation (ANG) and these three dimensions have 12 items and adopt 5-point scoring method. $\alpha$ coefficient of the scale is 0.82; $\alpha$ coefficient of POS subscale is $0.74 ; \alpha$ coefficient of DES subscale is $0.74 ; \alpha$ coefficient of ANG is 0.76 ; and the scale has good validity [11].

\subsection{Statistical Tool}

SPSS is adopted to sort valid data; and methods of descriptive statistics, independent sample t-test and one-way analysis of variance are adopted to perform statistical analysis.

\section{Results}

\subsection{Characteristics of Network Misconduct of College Students}

Network words misconduct includes making defamatory comments, adding water or refreshing maliciously, making improper comments and others $(\mathrm{M} \pm \mathrm{SD}=8.76+2.07)$; network study misconduct includes downloading materials to make a paper, copying answers when doing homework and others $(\mathrm{M} \pm \mathrm{SD}=7.40+2.17)$; network infringement includes downloading or using counterfeit software, downloading unauthorized music or video and others $(\mathrm{M} \pm \mathrm{SD}=5.21+2.16)$. See Table 1. Difference of network misconduct for students on genders is analyzed by independent sample $t$ test and the result indicates that average value of male students is 22.66 and standard deviation is 4.73; average score of female students is 19.33 and standard deviation is 3.27 ; $\mathrm{t}=$ $12.51, \mathrm{p}<0.001$; and the difference is great.

Result of analysis of variance in educational levels, majors and grades shows that: 1) For undergraduate and junior college students, mean square value between the groups is 878.164 ; mean square value within the group is 17.234; $\mathrm{F}=50.957, \mathrm{p}<0.001$, and the difference thereof is significant. 2) Mean square value between students of arts, science, engineering and medicine is 16857.756; $\mathrm{F}=23.840, \mathrm{p}<0.001$; and the difference is significant. Through multiple comparison afterwards, arts students get a much lower score than students of science, engineering and medicine do. 3) Mean square value between different grades is 1501.928 and mean square value within the group is 16626.194; $\mathrm{F}=28.576, \mathrm{p}<0.001$; and the difference is significant. Through multiple comparisons afterwards, scores freshmen get are much lower than that of students from other grades and scores sophomores get are much lower than that of juniors.

\subsection{Overview of Self-Efficacy Concerning College Students' Emotion Regulation}

Results of Table 2 show that the minimum values of POS and ANG are all 4, and the maximum values are 20; average value of POS is 15.6386 which is larger than its theoretical median 12; average value of ANG is 13.3713 which is larger than its theoretical median 12; minimum value of DES is 5 , the maximum value is 20 , and the average value is 13.9028 which is larger than its theoretical median 12; minimum value of aggregate score of RES is 16 , the maximum value is the full score 60 , and the average value is 42.9127 which is larger than its theoretical median 36 . There are great differences in the subscales of regulatory emotional self-efficacy for male and female students. Among which the POS score female students have a much higher score than male students $(\mathrm{t}=-5.991, \mathrm{p}<0.001)$; for the DES score, male students have a much higher score than female students $(\mathrm{t}=2.621, \mathrm{p}<0.01)$; for the ANG score, male students have a much higher score than female students $(\mathrm{t}=$ $2.408, \mathrm{p}<0.05$ ); for the RES score, there is no great difference between male students and female students. 
Table 1. Statistical table of basic information of network misconduct of college students.

\begin{tabular}{ccccc}
\hline Item & Min & Max & M & SD \\
\hline Network words misconduct & 8.00 & 25.00 & 8.76 & 2.07 \\
Network study misconduct & 4.00 & 16.00 & 7.40 & 2.17 \\
Network infringement & 3.00 & 17.00 & 5.21 & 2.16 \\
Total score of network misconduct & 15.00 & 47.00 & 21.37 & 4.72 \\
\hline
\end{tabular}

Table 2. Scores of self-efficacy concerning college students’ emotion regulation $(M \pm S D)$.

\begin{tabular}{ccccc}
\hline & Min & Max & M & SD \\
\hline POS & 4 & 20 & 15.6386 & 2.62788 \\
DES & 5 & 20 & 13.9028 & 2.59728 \\
ANG & 4 & 20 & 13.3713 & 2.83399 \\
RES & 16 & 60 & 42.9127 & 6.15040 \\
\hline
\end{tabular}

In the POS dimension, values for the majors $(\mathrm{M} \pm \mathrm{SD})$ are: arts students $=15.62 \pm 2.60$; students of science $=$ $15.71 \pm 2.80$; engineering students $=15.38 \pm 2.51$; students of medicine $=16.18 \pm 2.70\left(\mathrm{t}=3.964^{* *}, \mathrm{p}<0.01\right)$; students of medicine get much higher score than students of arts and engineering do. In the ANG dimension, values for the majors $(\mathrm{M} \pm \mathrm{SD})$ are: arts students $=13.24 \pm 2.77$; students of science $=13.94 \pm 2.76$; engineering students $=13.45 \pm 2.79$; students of medicine $=12.94 \pm 3.09\left(\mathrm{t}=4.511^{* *}, \mathrm{p}<0.01\right)$; in this dimension, students of science get much higher score than students of arts, engineering and medicine do. For the dimensions of DES $(\mathrm{t}=1.775, \mathrm{p}>0.05)$ and RES $(\mathrm{t}=2.047, \mathrm{p}>0.05)$, the difference in grades is not great.

\subsection{Correlation between Network Misconduct of College Students and Regulatory Emotional Self-Efficacy}

Results of Pearson correlations between three dimension of regulatory emotional self-efficacy-perceived selfefficacy in expressing positive affect (POS), perceived self-efficacy in managing despondency/distress (DES) and perceived self-efficacy in managing anger/irritation (ANG) and three dimensions of network misconduct of college students_-network words anomie, network study anomie and network infringement are shown in Table $\mathbf{3}$. Network misconduct has negative correlation with regulatory emotional self-efficacy and some was significantly negative correlation with the significance level lower than 0.01 .

\section{Discussion}

Definition of network misconduct. Network misconduct may cause serious harm to the society. Spreading bad information will be harmful to the society; rights and interests of various behavioral agents will be harmed; self-disorder of individuals as agent of network behavior will be harmful to the body and the mind, it may even interrupt or hinder the normal operation of the "network society” [3]. Many scholars conduct lots of questionnaire surveys on network misconduct from their own research angles, which enriches the experience of understanding and study of network misconduct; however, the classification of study content cannot be agreed on due to lack of normative definition of network misconduct. And sometimes, subjectivity cannot be avoided; for example, in research by some scholars, measurement of misconduct is conducted through three evaluation dimensions, including "I rarely do unethical staff online; sometimes I think about unethical things, but I can control it on the network; I will advise people not to do unethical things if I see them do that online"; subjects have different understandings concerning what is immoral; therefore, it is hard for this kind of measurement to reflect the extent of misconduct of the subjects. This study defines the network misconduct from four points of view of the network misconduct, i.e. problematic, harmful, non-pathological, and implemented on the internet, which helps to clear the study scope of network misconduct.

For college student, network misconduct including network words anomie, study anomie and infringement behavior, network words anomie is more prominent. Network words misconduct will make the network environment not harmonious; network study misconduct will be harmful to others' intellectual property rights and to the enthusiasm of learning and progress of college students and eventually leading to failure in study; network 
Table 3. Correlation coefficient of network misconduct and regulatory emotional self-efficacy.

\begin{tabular}{ccccc}
\hline & Network words misconduct & Network study misconduct & Network infringement & Total score of misconduct \\
\hline POS & $-0.154^{* *}$ & -0.006 & -0.006 & -0.064 \\
DES & -0.037 & -0.146 & -0.036 & $-0.098^{* *}$ \\
ANG & -0.009 & $-0.192^{* *}$ & -0.049 & $-0.124^{* *}$ \\
RES & $-0.087^{* *}$ & $-0.163^{* *}$ & -0.046 & $-0.134^{* *}$ \\
\hline
\end{tabular}

entertainment misconduct will cause web addiction for college students which is harmful for the development of their body and may cause psychological distortion. Confronting network misconduct, we should take measures to interrupt or prevent them.

There are significant differences of network misconduct for students on genders, education levels, grades and genders. For network misconduct of college students, scores of male students are much higher than that of female students (Average score of male students is 22.66 and standard deviation is 4.73; average score of female students is 19.33 and standard deviation is $3.27 ; \mathrm{t}=12.51, \mathrm{p}<0.001$; and the difference is great). This agrees with the conclusion of the study on implicit aggressivity and implicit self-esteem of people with network misconduct by Hu Zhihai which indicates that network civilization of female students is much better than that of male students with major part the subjects of network civilization being male students [1]. The scores of undergraduate students are higher than that of junior college students; there are differences in hardware facilities for colleges (or universities) and junior colleges which lead to the differences in the convenience and length of time of accessing the internet. Convenience and length of time of access to internet will affect the occurrence of network misconduct. In the aspect of major, arts students get lower scores than students of other majors do; the probable reason is that cultural deposit and accomplishment of arts students are better than that of students of other majors; good cultural accomplishment has positive influence on the moral quality and behavior of individuals, thus it decreases the occurrence of network misconduct. In addition, network misconduct of freshmen are significantly less than that of students from other grades; the probable reason is that freshmen have just left the intense study environment, having little access to the internet, thus they are affected by the internet less.

Result of correlation between network misconduct of college students and regulatory emotional self-efficacy is significantly negative correlation, which indicates that individual with good regulatory emotional self-efficacy has less network misconduct. In the view of correlations of dimensions, regulatory emotional self-efficacy has significantly negative correlation with network words anomie and network study anomie and does not have significantly negative correlation with network infringement behavior; the probable reason may be that compared with infringement behavior, words and study behaviors include more emotional factors, and thus they affect the correlations.

\section{Acknowledgements}

This paper is one of the stage achievements for soft science project (project No.: 122400450116) of Henan Science and Technology Department.

\section{References}

[1] Zhang, D.M. (2011) Study on Network Misconduct of College Students. Ocean University of China, Qingdao.

[2] Zheng, P.G. and Li, X.D. (2008) Investigation and Analysis on Network Misconduct of College Students. Heilongjiang Researches on Higher Education, 176, 126-129.

[3] Li, Y. (2007) Morphologic Expression, Social Harm and Management Measures of Network Misconduct. Inner Mongolia Social Sciences, 28, 121-125.

[4] Lian, L. (2007) Study on Network Misconduct. Zhengzhou University, Zhengzhou.

[5] Zhou, L.F. (2012) Study on Network Misconduct of College Students Who Were Born after 1990—Taking Putian University as an Example. Fujian Normal University, Fujian.

[6] Yu, H.L. (2011) Preparation and Application of Questionnaire of Network Misconduct of College Students. Nanjing Normal University, Nanjing.

[7] Hu, Z.H. (2009) Study on Implicit Aggressivity and Implicit Self-Esteem of People with Network Misconduct. Journal of Psychological Science, 32, 210-212. 
[8] Zhang, W.M. (2006) Network Misconduct of College Students and Ideological and Political Education. Journal of Anyang Normal University, 4, 20-21.

[9] Zhang, J.S. (2012) Construction of Prevention Model for Network Misconduct of College Students-Based on the Theory of Constraints. Theory and Practice of Education, 32, 29-31.

[10] Mitchell, P. (2000) Internet Addiction: Genuire Diagnosis or Not. The Lancet, 355, 632. http://dx.doi.org/10.1016/S0140-6736(05)72500-9

[11] Zhang, P., Zhang, M. and Lu, J.M. (2010) Trial Analysis on Application of Emotional Self-Efficacy Scale to Chinese College Students. Chinese Journal of Clinical Psychology, 18, 568-570. 